\title{
The Effect of Energy Policies in Turkey on Transportation Sector: The analysis of energy related price and cost in road transportation
}

\author{
Celil DURDAĞ $\breve{G}^{1}$ Ersin ŞAHIIN ${ }^{2}$ \\ ${ }^{1}$ Celil Durdăg, Beykoz Vocational School of Logistics, Transportation Services Department, Civil Aviation Cabin Services \\ Program, Istanbul, Turkey, celildurdag@beykoz.edu.tr \\ ${ }^{2}$ Ersin Sahin, Beykoz Vocational School of Logistics, Management and Organization Department of Energy Facilities \\ Management Program, Istanbul, Turkey,ersinsahin@beykoz.edu.tr
}

\begin{abstract}
Energy policies are seriously affecting economic and social life all over the world as well as in Turkey. When the supply process from the energy resource to the consumer increases in energy cost depending on transport type it has important influence. Increase in energy costs in the supply chain is undertaken by all stakeholders. In this study, we examine at which level road transportation costs, which is the most predominant type of transportation in Turkey is influenced by energy consumption with reference to the energy policies of Turkey and energy consumption of Turkish transportation sector. Thus certain suggestions reducing energy costs have been made to all parties in the supply chain by considering the distribution between energy related costs and other costs.
\end{abstract}

Keywords: Energy, Supply Chain, Transportation

\section{AN OVERVIEW OF ENERGY CONSEPT}

Energy, one of the base quantities of Physics. Energy is a conservative magnitude, it can not be fragmented as it can not be destroyed but it can convert from one form to another. During this conversion process energy loses occur these loses cause unproductiveness. The form of energy which is converted or transformed is called "Primary Energy". Primary energy resources: coal, crude oil, natural gas, nuclear, hydraulic, bio-mass, tidal-wave, sunlight and wind [Figure 1]. Conversion of primary energy creates a new energy that called "Secondary Energy". Electric, gasoline, diesel oil, coking coal, liquefied petroleum gas are the examples for secondary energy resources. Energy resources on the Earth are divided into two by their generation, fossil and renewable. Fossil (exhaustible) energy resources; hard coal, crude oil, natural gas, uranium, lignite, turf, thorium and asphalt[Table 1]. Because of their generation take ages, they are non-regenerative energies, due to uncertainty in reserves their costs are increasing. Renewable (natural) energy sources classified as solar energy, wind energy, hydraulic energy, geothermal energy, sea origin energies (wave or tidal) Renewable energy sources are less harmful sources than fossil energy sources. This sources are sources which, generally available on the earth and nature without need for any production process, during production of electricity $\mathrm{CO}_{2}$ emission occur, regenerate with continuous motion and existing in nature as ready to use [1].

\subsection{Energy resources and reserves in Turkey and the world}

When we look at the fossil energy resources in the world, there is no problem about their sufficiency. Known producible energy reserves are enough for different time levels such as petrol for 40 years, natural gas for 62 years, and coal for 216 years.

Table 1. World Fossil Fuels Status

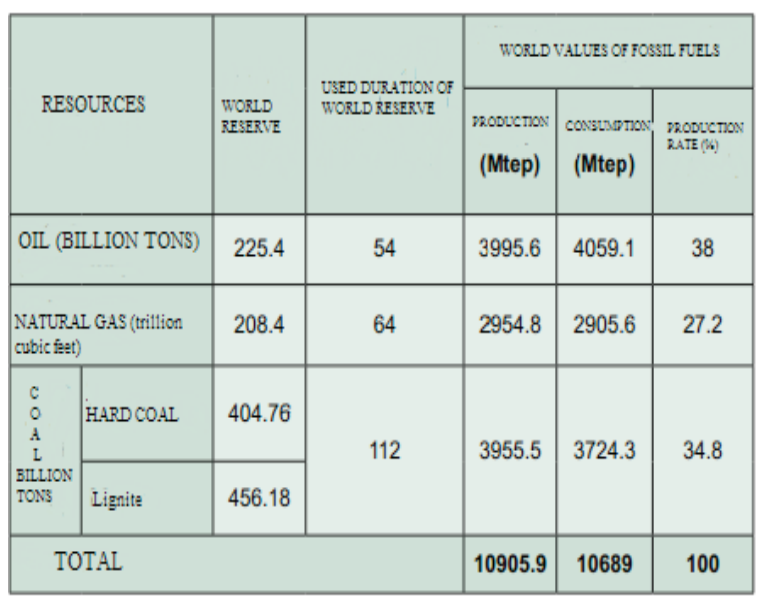

Corresponding Author: Celil Durdağ, Tel: +90 (212) 4440 413, E-mail: celildurdag@beykoz.edu.tr, Submitted: 21 October 2015, Revised: 24 December 2015, Accepted: 10 February 2016 
In Turkey according to an opinion, which has been around since 80 's, turkeys local energy resources are so little that even if all of them are used, they cannot cover energy gap [Figure 2]. In contrast to this Turkey, especially in two resources, is in a lucky condition. These are, hydroelectric which is a clean and renewable resource and lignite which is more than 8 billion tons. However, these resources are not used efficiently in energy producing [2]. According to statistics only 33 percent of our hydraulic and coal resources are used effectively. Our lignite reserves should be used much more efficiently than it already has, especially in clean burning technology stations. In according to this, new researches are clearly suggest that our hydraulic resources 125 billion kwh of which is accepted as economically usable, can be increased to 160-180 billion kwh for the use [3].

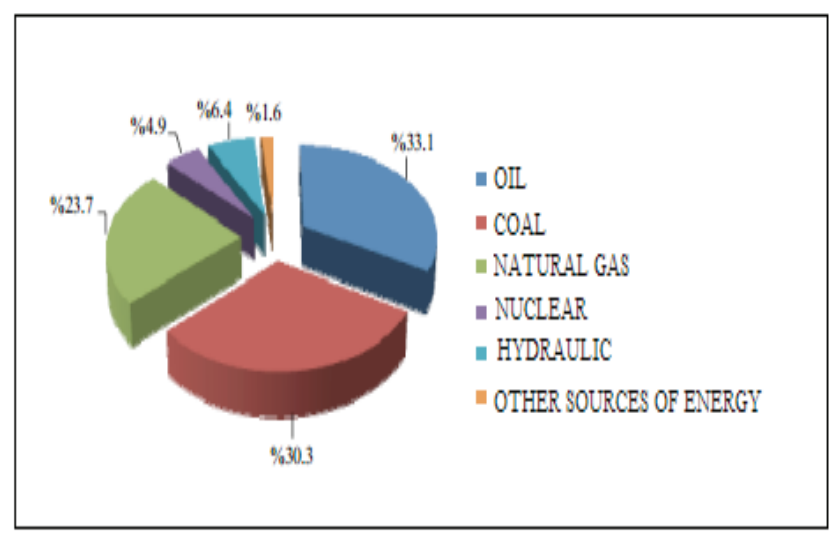

Figure 1. World Primary Energy Usage in 2011

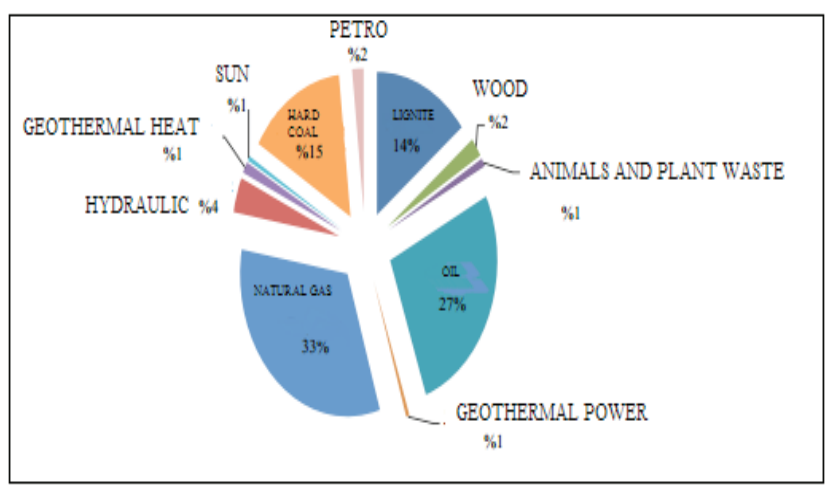

Figure 2. Energy Consumption on Sources Bases in Turkey

\subsection{Fuel Consept, Fuel Types and Heating Values of Some Fuels}

Materials, which they chemically or physically changed when they were burnt, called fuel. Generally speaking, fuels are divided into three different groups: solid fuels, liquid fuels, gas fuels. Nowadays, the energy which we have been using is provided from solid fuels. Population growth, urbanisation, and industrialization cause energy consumption to become high. Running out of energy sources ends up with high prices. Energy value at unit mass or volume is named heating value. Heating value of fuels is a characteristic feature that means energy as a result of burning procedure [Table 2]. It is important that preferring fuels which have high figures of heating value in the aspect of decreasing energy costs [4].

Table 2. Heating Values of Some Fuels

\begin{tabular}{cc}
\hline Fuel Type & Heating Value $(\mathbf{M J} / \mathbf{k g})$ \\
\hline Hard Coal & 25.53 \\
Crude Oil & 43.96 \\
LPG & 45.63 \\
Wood & 12.56 \\
Acetylene & 59.57 \\
\hline
\end{tabular}

\section{ENERGY POLICIES IN TURKEY AND TRANSPORT SECTOR'S PLACE IN ENERGY POLICIES}

The main purpose of Turkey's Energy Policy is providing energy to the consumers in the manner of realizing economic growth and promoting social development; on time, adequate, with competitive prices, consider environmental effects.

In this case, main policies and strategies of our country are summarized as below:

- Expanding storage capacities of strategic petroleum and natural gas

- Diversification of sources and countries

- Give priority to using and developing of local sources

- Using, developing of different technologies and improving local producing

- Benefit in the best way from our country's potential of being energy trace center

- Activating of demand management and increasing its productivity

- Increasing fuel flexibility (allow for using alternative energy sources in production)

- Ensuring participation in every stage of transport process of Middle East and Caspian's petroleum and natural gas 
- Configuration of energy sector with predicate clearness and competition on as a acting market

- Participate in regional cooperation projects and integration

- In every stage consider environmental effects [3].

Turkey's primary energy consumption's $13.9 \%$ and primary petroleum consumption's $50.8 \%$ used in transport sector. Almost all of the energy used in the transport sector $(97.1 \%)$ is petroleum products. Turkey's petroleum production compensate only $7-9 \%$ of consumption and remaining $91-93 \%$ part is compensated with importation, therefore it can be said that energy saving and efficient use of energy in transport sector has a great importance. Energy is not the only factor that affects choosing transport type, but it's an important factor and getting more important. So, getting more economical form to transport sector from the point of energy consumption is becoming an important situation [6].

Economic growth, environmental degradation, energy and transport policies should be recognized in order to improve the energy efficiency in transport sector. All measures that should reduce petroleum consumption and greenhouse gas emissions without affecting economic growth may be undertaken. To evaluate the energy sustainability degree of transport sector, it is necessary to determine the driving factors influencing transport-related energy consumption such as economic growth, energy price, urban population, transport activity, motorization rate, traveling distance, park structure, vehicle types, vehicle age, urbanization, national road network and transport intensity. The main objective was to define cause and effect relationships between these indicators in order to formulate appropriate policies increasing the energy sustainability in the transport sector [15].

\subsection{Energy Consumption in Road Transport and Highway} Transportation in Turkey

Located largest share in road transport modes of transport in Turkey is generally held to 5 species [Figure 3].

They are;

- Walk

- Bicycles

- Motorbikes

- Private Cars

- Public and School Buses

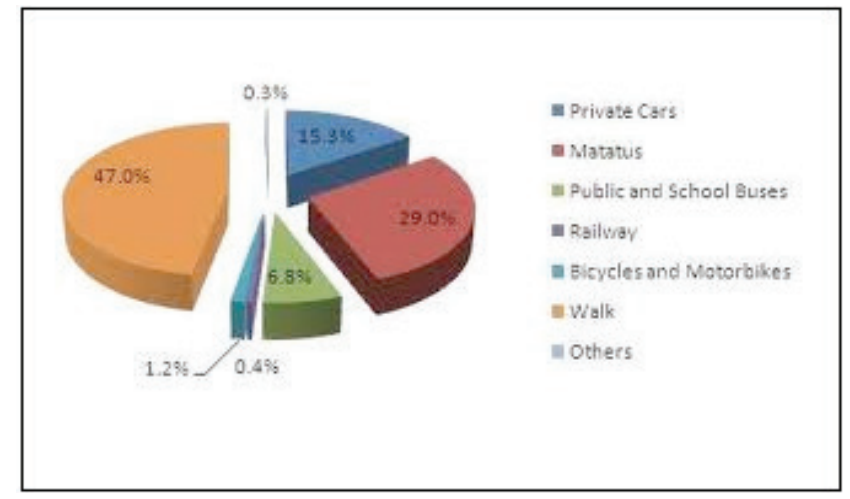

Figure 3. Dispersion of Road Transport Type in Turkey [1]

Fuel is not required for the pedestrian and bicycle transportation but for the most common fuel oil for other transport systems. Made with motorcycle transportation needs less energy than a car and public transport. Public transport is the high fuel consumption, although a number of the most useful transportation system to carry passengers and that has occupied the lowest passenger area.

2.1.1 Dispersion and Alternative Fuels Pursuit of Energy Resources Used in Road Transport in the world and Turkey

In Turkey there are 17,579,349 units of motor vehicles by the end of July 2013. Data for the year 2012 only if we look at the type of fuel the vehicle stands out in our country. Accordingly, a total of $17,033,413$ pieces of the vehicle in 2012;

- 5,722,940 units Benzine

- 7,549,806 units Diesel

- 3,649,739 units LPG 110,928 units vehicles are not known.

In 2012 the world 89.8 million b / d (barrels / day) oil consumption was. The year 2012 has increased to 1.637 billion barrels of oil reserves in the world increased from $7.7 \%$ to 1.520 billion barrels. 44.8 years in 2011. This increase, together with the life of oil reserves has increased to 48.8 years in 2012. In Turkey, in 2012, oil production was 2.3 million tons. Recent gas than petroleum derivatives have also started to be used as a vehicle fuel. These fuels are Liquefied Natural Gas (LNG) and compressed natural gas (CNG). World in 2012 3,348.7 billion $\mathrm{m} 3$ of natural gas consumption was. Beginning of 2011, the year 57.96 3\% increase in production of natural gas reserves in life that occurred at the beginning of 2012, and slightly decreased to 57.07 years due to the amount of natural gas reserves. Oil is becoming more of a source used for the transport sector. Average of $60 \%$ of the oil consumed in OECD countries 
is used for transportation. In some countries this rate is up to $75 \%$. In most of the developing countries, this rate is around $40 \%$. Utilization of natural gas in the car is low [5]. Alternative energy sources and technologies for heating, power and electricity production partially fill the place of oil, it does not seem possible, but more so in the near future a substitute fuel in the transport sector on a global scale. Today it is $20 \%$ in the transport sector's share in the global energy consumption, $3 / 4$ of it is seen that go to road transport. Considering oil is still used as the main fuel for vehicles traveling on the highways, unless an affordable alternative canto replace fuel oil will continue importance of oil be found to maintain at least the first half of this century [7]. The new energy sources are alternative fuels for motor vehicles. Sustainable energy supply can continue to be provided with alternative fuels. Besides reducing the environmental pollution is the subject of alternative fuels promise. NEV is defined as the four-wheel vehicle using unconventional vehicle fuel as the power source, which includes hybrid vehicle(HV), battery electrical vehicle (BEV), fuelcell electric vehicle (FCEV), hydrogen engine vehicle (HEV), dimethyl ether vehicle (DEV) and other new energy (e.g.high efficiency energy storage devices) vehicles. NEV is also one of the most important future road transport Technologies which has attracted a growing attention from both the industry and academics [14]. The main conclusion of the analysis is that it is not possible to point to one technology/fuel as the best option. In fact, the most solid recommendations concerns options that are not favourable in terms of energy efficiency. The electric vehicle is, and most likely will continue to be, a considerably more energyefficient option than hydrogen, at least for electricity as a starting point. On the other hand, the issue of the vehicle range points to hydrogen as the superior fuel rather than electricity, and hydrogen vehicles can in principle become very similar to conventional vehicles in the future [9]. Regional and local environmental impact can motivate the use of alternative fuels instead of petrol and diesel in certain traffic situations, even if the cost of $\mathrm{CO} 2$ emission is not regarded. Then it is the fossil-based alternatives (natural gas or fossil-based methanol) that are competitive. At current $\mathrm{CO} 2$ tax level biogas from waste is competitive where no natural gas is available. To enable a greater use of biomassbased fuels, the economic valuation of $\mathrm{CO} 2$ emission would have to be $2 \pm 2.5$ times higher than current $\mathrm{CO} 2$ taxes [13].

The economic valuation of regional and local environmental impact is important in making alternative fuels viable. Future valuations of local and environmental impact are difficult to assess as the knowledge of the damage due to different pollutants will increase. Furthermore, the economic valuation of environmental impact may increase with time. Such an increase in environ-mental concern will improve the competitiveness of low-polluting transportation fuels [13].

The continuing reductions in emission factors for diesel and petrol will, however, reduce the absolute advantage of using alternative fuels. The cost efficiency of improving vehicles for conventional fuels instead of using alternative fuels has, however, not been studied since cost data for such improvements have not been available [13].

\section{CAlCUlating THE COST OF ENERGY AND FUEL COSTS FOR ROAD TRANSPORT}

The total energy cost was calculated as the sum of the direct energy cost (fuel and lubricant consumption) and indirect energy cost (energy used for the vehicle construction). Excess demand on goods and private road transport may cause to increase transport cost It is divided into two groups: Internal and external. Estimation of internal cost is easy, but of external cost is difficult. The both internal and external cost of the highway transport needs to be decreased. Litman (1998) obtained the transport cost as $0.35 \$ /$ pass $-\mathrm{km}$ [11]. At the present, energy costs are rising sharply, and fossil fuel prices are likely to remain consistently high or even increase in the near future. Increasing energy costs have a differing influence on the cost of truck, ship and rail transport [10]. The fuel price increases have an impact on the variable costs of transport modes [12]. Road transport-related energy consumption, transport value added, transport $\mathrm{CO} 2$ emissions and road infrastructure are mutually causal in the long-run. Also, there is a unidirectional causality running from fuel price to road transport-related energy consumption with no feedback in both the short and long runs. The fuel price and the road infrastructure are significant in the causal chain [15]. There are many type of road tax for motorized vehicles in Turkey. It can be classified into two main groups: static and dynamic. Static tax can be defined as the yearly tax that is taken from motorized vehicles (MOT) according to their age, weight and cylinder capacity as well as the tax is paid by purchase (PT). In addition, the vehicle insurance (VIT) and the Motor Inspection (MIT) taxes are also compulsory and static. Dynamic road tax can be defined as the fuel tax (FT) that vehicle users pay during the purchase of the fuel [11]. The most important variable is the cost of road transport in fuel expense represents the fuel expenses 
incurred during the journey. One of the most important items of costs incurred in a road time is fuel costs. Of the most important cost of fuel goes, there are two main reasons. They are; fuel consumption of commercial vehicles is more than periodic hikes in the fuel unit costs are day by day and periodically heavy tax in Turkey. For use as fuel expenses at the highest rate in the variable costs should be monitored regularly. Fuel expenses floor of the vehicle with the route length and the vehicle (tractor or truck) is associated with the fuel consumption rate. Fuel consumption per kilometer is calculated by dividing the total consumption of kilometers to be traveled. The fuel cost per time with the amount of fuel used during the time the fuel is calculated by multiplying the unit price. Fuel unit price may vary. Because every fuel purchase unit price is not the same. In addition, the determination of the total mileage that the vehicle's empty miles with the total installed performs during a time, it is important to calculate the true cost [8].

Table 3. Oil Prices [2005-2050]

\begin{tabular}{|c|c|c|c|c|c|c|c|}
\hline \multirow[t]{2}{*}{ Year } & \multicolumn{3}{|c|}{$\begin{array}{l}\text { Resource cos for } \\
\text { petrol (penceft) }\end{array}$} & \multicolumn{3}{|c|}{$\begin{array}{l}\text { Resousce cost for } \\
\text { dierel (pencelli) }\end{array}$} & \multirow[t]{2}{*}{$\begin{array}{l}\text { Resource cost of donestic } \\
\text { electricity supply (penceltwh) }\end{array}$} \\
\hline & Low & Central & Hight & Low & Central & Highh & \\
\hline 2005 & 30.76 & 30.76 & 30.76 & 34.41 & 3441 & 34.41 & 11.72 \\
\hline 2010 & 42.57 & 42.57 & 42.57 & 4,31 & 4431 & 4,31 & 1235 \\
\hline 2015 & 47.50 & 53.06 & 6200 & 48,38 & 5901 & 68.96 & 16.20 \\
\hline 2020 & 40.58 & 56.35 & 70.65 & 45.14 & 6268 & 78.59 & 1796 \\
\hline 2025 & 37.85 & 59.83 & 80.55 & 42,10 & 6655 & 89.59 & 19.74 \\
\hline 2030 & 3.31 & 63.55 & 91.80 & 39.27 & 70699 & 102.11 & 20,60 \\
\hline 2035 & 34.95 & 64.17 & 92.69 & 38.89 & 7138 & 103.10 & 20.29 \\
\hline 2040 & 34.62 & 64.79 & 93.59 & 38.51 & 7207 & 104.10 & 19.22 \\
\hline 2045 & 34.27 & 65.41 & 94.48 & 38.12 & 7276 & 105.09 & 19.22 \\
\hline 2050 & 33.93 & 66.03 & 95.38 & 37.74 & 7345 & 106,09 & 19.17 \\
\hline
\end{tabular}

\section{CONCLUSIONS AND RECOMMENDATIONS}

Energy issues seem to protect importance in today and the future. Show an upward trend in all scenarios set out in the perspective of oil prices in 2050 will directly affect the country's economy [Table 3]. Working with existing technologies in the short term, especially in the field of transport vehicles powered by alternative fuels, petroleum products, car shows up not widespread. However, this need in terms of countries dependent on foreign oil as well as Turkey's economic balance will not change the fact that they should work on alternative fuels to lose its competitive advantage in strategic sectors such as transport. Distance of the fuel cost increase in road transport is known to be proportional with. Combined transport applications widely applied in the reduction of fuel costs. However, do take advantage of combined shipping facility's every move is not possible. Therefore, to reduce the fuel cost of road- based transport energy radical solutions are needed. The vast majority of Turkey's energy consumption is met by oil and gas. Basic point of Turkey's gradual improvements to be made to reduce the energy costs will be seen in transportation. Turkey should ensure that its work with high calorific values of fuels vehicles carrying passengers and cargo, especially in the period ahead. The government should provide the necessary support to increase their share of vehicles running on alternative fuels in the presence of total vehicles in Turkey. The alternative fuel vehicles, except the government's legal requirements should direct the correct transport stakeholders. Besides being more cost of fuel produced from oil and its derivatives is known that polluting effect of high emission levels. Turkey should give priority to research and development activities for the production of vehicles powered by hydrogen energy. Turkey's civil society organizations and academics also have duties outside the government in increasing the profitability of the transport sector by reducing the lower carbon emissions to improve the quality of life using the tools and perform the fuel in transportation costs. Turkey's civil society organizations can create their studies with the public to increase the preferred alternative fuel vehicles. Academics can illumine society and transport stakeholders with the scientific studies.

\section{REFERENCES}

[1] Koç, E., Şenel, M. C. (2013). "Energy Situation Overview in the World and Turkey," Mühendis ve Makina, cilt 54, say1 639 , s. 32-44

[2] Öztürk,H.Hüseyin.,YIL, (2013) , Renewable Energy Resources, Birsen publishing house, March

[3] Thermal power plants in Turkey, Koray TUNCER, (2013), Mechanical Engineer ROOM Chamber of mechanical engineers

Energy Unit

[4] Pamir, A. Necdet., (2003), Energy in the World and Turkey, Turkey's Energy Resources and Energy Policies,

[5] Gür, Aslan., (2013), Energy Efficiency in Road Transport and Diversification of Energy Sources, Ankara

[6] Solak, A. O., (2013), Reducing Energy Consumption of Transportation Sector in Turkey: A Scenario Approach, Journal of Economic and Social Research, 1, 125-140.

[7] Bayraç, H. H., (2005), Economic Analysis of International Oil Market, Eskişehir.

[8] Ercan, Melis., (2006), The Costing System in International Road Freight Transportation and an Application, Istanbul University Social Sciences Institute, Istanbul.

[9] Jorgensen, K, (2008), Technologies for Electric, Hybrid and Hydrogen Vehicles: Electricity from Renewable Energy Sources in Transport, Utilities Policy, 16, 72-79.

[10] Rauch, P, Gronalt, M, (2011), The Effects of Rising Energy 
Costs and Transportation Mode Mix on Forest Fuel Procurement Costs, Biomass and Bioenergy, 35, 690-699.

[11] Haldenbilen, S, Ceylan, H, (2005), The Development of a Policy for Road Tax in Turkey, Using a Genetic Algorithm Approach for Demand Estimation, Transportation Research Part A, 39, 861-877.

[12] Macharis, C, Hoeck, V, E, Pekin, E, Lier, V, T, (2010), A Decision Analysis Framework for Intermodal Transport: Comparing Fuel Price Increases and The Internalisation of External Costs, Transportation Research Part A, 44, 550561.
[13] Johansson, B, (1999), The Economy of Alternative Fuels When Including The Cost of Air Pollution, Transportation Research Part D, 4, 91-108.

[14] Yuan, X, Liu, X, Zuo, J., (2014), The Development of New Energy Vehicles for A Sustainable Future: A Review, Renewable and Sustainable Energy Reviews, 42, 298-305.

[15] Abdallah, B, H, Belloumi, B, Wolf, D, D, (2013), Indicators for Sustainable Energy Development: A Multivariate Cointegration and Causality Analysis from Tunisian Road Transport Sector, Renewable and Sustainable Energy Reviews, 25, 34-43. 